\title{
Perspective of enhancing wheat production and productivity in Uttar Pradesh by improving varietal replacement rate
}

Amit Kumar Sharma ${ }^{1}$, Chandra Nath Mishra ${ }^{1}$, Bishnu Pratap Singh ${ }^{2,}$ Sanjay Kumar Singh ${ }^{1 *}$ and Gyanendra Pratap Singh ${ }^{1}$

${ }^{1}$ ICAR-Indian Institute of Wheat and Barley Research, Karnal

${ }^{2}$ Department of Agriculture and Farmers Welfare, Govt. of UP, Lucknow

Article history: Received: 5 Apr., 2020 Revised: 28 Apr., 2020, Accepted: 02 May., 2020

Citation: Sharma AK, CN Mishra, BP Singh, SK Singh and GP Singh. 2020. Perspective of enhancing wheat production and productivity in Uttar Pradesh by improving varietal replacement rate. Journal of Cereal Research 12(1):19-22. http://doi.org/10.25174/2582-2675/2020/100826

*Corresponding author: E-mail: sanjay.singh4@icar.gov.in

(c) Society for Advancement of Wheat and Barley Research

\section{Introduction}

Wheat is the major staple food crop and a major source of energy for Indian population. India has achieved remarkable progress in wheat production during the last 4 decades and is continue to be second largest wheat producing nation in the world. The wheat production has increased manifold from 6.60 million tonnes at the time of independence to 107.18 million tonnes in during 2019-20 (Anonymous, 2020a). Based on climate, crop duration and soil type, India has been divided into five major wheat growing zones namely North Western Plains Zone (NWPZ), North Eastern Plains Zone (NEPZ), Central Zone (CZ), Peninsular zone (PZ) and Northern Hills zone (NHZ), thus accounting for 29.71 mha area under wheat cultivation. Although Punjab and Haryana have highest wheat productivity at national level, UP state has maximum contribution to the national food basket in terms of total wheat production to the tune of more than $30 \%$ alone. State-wise wheat area and production trends showed Uttar Pradesh, Punjab, Madhya Pradesh and Haryana as the major contributors to the national wheat production. Among these states, Punjab, Haryana and Uttar Pradesh retained higher productivity for many years. The scope for additional production of these states has been limited due to stagnation of wheat acreage and yield that indicated a kind of saturation level of wheat cultivation and production in these states.
2. Area, production and productivity trend in Uttar Pradesh

UP state has uniqueness being part of three major mega zones namely NWPZ (28 districts of western UP), NEPZ (42 districts of central and eastern UP) and CZ (5 districts of Bundelkhand region). Among these, the areas under NWPZ represent high fertility areas whereas the Bundelkhand region in $\mathrm{CZ}$ represents the marginal areas having water stress conditions. Despite of these variations, UP is continuously highest wheat producing state in the country that contributes approx. $32 \%$ wheat in national wheat basket. The production trend in UP in last 5 years have shown tremendous improvement as shown in Table.1. Although the area under wheat is almost remains same, the production has been increased due to enhanced yield levels that surpassed the national average during 2018-19. The major reason for this yield jump is adoption of new wheat varieties to a large extent by the farmers. The Indo Gangetic plains characterized by deposition of fine alluvial soil by the river Ganges and its tributaries and a close network of canals, supplemented by large number of tube wells have helped U.P. to occupy the top position in wheat production. About $75 \%$ of the wheat area lies in two major doabs in UP namely, the Ganga-Ghagra doab and Ganga-Yamuna doab. About 55 districts of Uttar Pradesh produce wheat as primary crop out of which 42 districts are the leading producers.

Table.1: Wheat production trends of India and UP State in last 5 years

\begin{tabular}{|c|c|c|c|c|c|c|c|c|c|}
\hline \multirow[t]{2}{*}{ Year } & \multicolumn{2}{|l|}{ India } & \multicolumn{3}{|c|}{ Uttar Pradesh } & \multicolumn{4}{|c|}{$\%$ of national value } \\
\hline & $\begin{array}{c}\text { Area } \\
\text { (m ha) }\end{array}$ & $\begin{array}{c}\text { Production } \\
\text { (m tones) }\end{array}$ & $\begin{array}{l}\text { Yield } \\
\text { (g/ha) }\end{array}$ & $\begin{array}{c}\text { Area } \\
\text { (m ha) }\end{array}$ & $\begin{array}{c}\text { Production } \\
\text { (m tones) }\end{array}$ & $\begin{array}{l}\text { Yield } \\
\text { (q/ha) }\end{array}$ & Area & Production & Yield \\
\hline 2014-15 & 31.5 & 86.53 & 27.47 & 9.85 & 22.42 & 22.77 & 31.3 & 25.9 & 82.9 \\
\hline $2015-16$ & 30.2 & 87.00 & 28.80 & 9.65 & 25.43 & 26.36 & 32.0 & 29.2 & 91.5 \\
\hline 2016-17 & 30.8 & 98.51 & 31.98 & 9.66 & 30.06 & 31.13 & 31.4 & 30.5 & 97.3 \\
\hline $2017-18$ & 29.7 & 99.87 & 33.63 & 9.75 & 31.88 & 32.69 & 32.8 & 31.9 & 97.2 \\
\hline 2018-19 & 29.9 & 102.19 & 34.18 & 9.54 & 32.74 & 34.32 & 31.9 & 32.0 & 100.4 \\
\hline
\end{tabular}

Source: http:// upagripardarshi.gov.in/ staticpages/ RabiStatistics.aspx) 


\section{The varietal spectrum in UP state}

As the UP state has very wide range of climatic conditions and has areas under three different wheat mega zones, there is varietal mosaic in UP states suitable to different agro-ecological conditions. In wheat, there is three major production conditions namely timely sown irrigated condition where wheat is sown during November $1-15^{\text {th }}$ and crop has optimum maturity duration, late sown irrigated conditions where wheat is grown during December 5-15 after harvest of paddy, sugarcane, early pea/potato, etc. and timely sown restricted irrigated condition where crop is sown in $1^{\text {st }}$ fortnight of November but get only 1-2 irrigation for wheat production. Based on very stringent evaluation under AICRP on Wheat and Barley, a number of wheat varieties have been released and notified by the Central Varietal Release Committee and recommended for commercial cultivation during last 10 years (Table.2).
In addition, delayed sowing, poor plant stand, low yield levels, non-availability of quality inputs, lack of farm machinery, poor soil health, low input use efficiency, weeds infestation, competition with other crops like rabi maize due to intensive cropping, lack of technological awareness (Joshi et al., 2007), irrational use of resources; changing disease and pest spectrum, problematic soils especially salt affected soils, non-availability of improved seed due to mismatch between formal (organized) and informal (unorganized) varietal dissemination and adoption system, price fluctuations, decline in farm size and conversion of farmland to residential areas, declining total factor productivity and poor extension services are the prominent challenges put forth against wheat production. (Chatrath et al., 2007, Anonymous, 2015).

\section{Strategies to enhance wheat production}

The strategies to address these production constraints can be categorized as wheat improvement, management,

Table 2: Improved wheat varieties recommended for UP state during last 10 years

\begin{tabular}{|c|c|}
\hline Production condition & Recommended varieties \\
\hline North West & rn Plains Zone comprising western UP \\
\hline Timely Sown, irrigated (high fertility) condition & $\begin{array}{l}\text { DBW222, DBW187, DBW88, HD2967, HD3086, HD3226, PBW723, } \\
\text { HPBW01, WB2, WH1105 }\end{array}$ \\
\hline $\begin{array}{l}\text { Late Sown, irrigated (medium fertility) } \\
\text { condition }\end{array}$ & $\begin{array}{l}\text { PBW771, PBW752, DBW71, DBW90, DBW173, HD3059, WH1124, } \\
\text { HI1621(VLS), HD3271(VLS), PBW757(VLS) }\end{array}$ \\
\hline $\begin{array}{l}\text { Timely sown, Restricted irrigation/ rainfed } \\
\text { (low fertility) condition }\end{array}$ & $\begin{array}{l}\text { HI1628, HD3237, HI1620, PBW660, WH1142, PBW644, WH1080, } \\
\text { HD3043 }\end{array}$ \\
\hline \multicolumn{2}{|c|}{ North Eastern Plains Zone comprising central and eastern UP } \\
\hline Timely Sown, irrigated (high fertility) condition & HD3249, DBW187, HD3086, HD2967, K307, K1006, NW5054, Raj4120, \\
\hline $\begin{array}{l}\text { Late Sown, irrigated (medium fertility) } \\
\text { condition }\end{array}$ & DBW107, HD2985, HD3118, HI1621(VLS), HD3271(VLS) \\
\hline $\begin{array}{l}\text { Timely sown, Restricted irrigation/ rainfed } \\
\text { (low fertility) condition }\end{array}$ & DBW252, HI1612, K1317, HD3171 \\
\hline \multicolumn{2}{|c|}{ Central Zone comprising Bundelkhand region } \\
\hline Timely Sown, irrigated (high fertility) condition & HI8759(d), HI8737(d), HD4728(d), HI8713(d) \\
\hline Late Sown, irrigated (medium fertility) & MP3336, MP1203 \\
\hline $\begin{array}{l}\text { condition } \\
\text { Timely sown, Restricted irrigation/ rainfed } \\
\text { (low fertility) condition }\end{array}$ & DBW110, Raj4238, DDW47(d), UAS466(d), HD4672(d) \\
\hline & All Zone \\
\hline Saline and alkaline conditions & KRL 210 and KRL 213 \\
\hline
\end{tabular}

\section{Production constraints and challenges to wheat production}

The wheat crop cultivation in India especially in UP is exposed to manifold production constraints that vary between regions. The growing demand in tune to increasing population is major bottleneck alongwith crop vulnerability in context to climate change conditions (Sendhil et al., 2018). As crop vulnerability is concerned, a significant area in UP is exposed to moderate to high terminal heat stressed areas. It has been predicted that with every rise in $1^{\circ} \mathrm{C}$ temperature, the wheat production will be decreased by $4-6$ million tonnes under best management conditions whereas rainfed wheat will experience a reduction in yield with $9-25 \%$ profit loss for every $2-3.5^{\circ} \mathrm{C}$ rise in temperature (Aggarwal., 2009). technological dissemination and policy planning strategies. Among wheat improvement strategies, bridging yield gaps and increasing productivity through developing climate resilient wheat genotypes in system perspective is important (Yadav et al., 2010). For this several approaches may be undertaken like exploitation of heterosis for developing hybrids, pre-breeding for broadening the genetic base, churning the biodiversity for varying traits, precision phenotyping, novel allele mining, development of new plant types with desired canopy structure, rapid leaf area development, efficient nutrient uptake, increasing lodging resistance with robust stem and biotechnological interventions for marker-assisted breeding. The crop management strategies through manipulating production technologies like ensuring availability of quality inputs 
(Singh et al., 2017), timely sowing, optimum plant stand for higher yields, managing adverse effects of climate change, promoting farm mechanization, adoption of RCTs especially zero tillage for high yield and net returns, increasing resource use efficiency, improving soil health through balanced fertilization, green manuring may be advantageous. Efficient technological dissemination through use of IT tools, farm advisory and market intelligence, upscaling improved technologies through economic assessment, creating awareness among farmers of new improved varieties and production technologies for yield as well as income enhancement (Sendhil et al., 2017) are supportive link between research institutions and farmers that help in enhancing farm productivity and profitability. The policy reorientation for price, seed, credit availability to farmers, Infrastructure development (roads, storage structures, market) and Institutional innovations like e-National Agriculture Market are some of the policy issues to be considered for enhanced production (Nagarajan, 2005).

\section{Strengthening seed sector for enhanced production}

Uttar Pradesh is highest wheat producing state in the country contributing about 32 per cent production with the productivity of $34.32 \mathrm{q} / \mathrm{ha}$. UP state also has maximum acreage of wheat (approx. 32\%) as compared to other leading states. The area remains almost same during last 5 years but there was increasing trend in wheat production in the state from $20.05 \mathrm{~m}$ tons in 2014-15 to $32.74 \mathrm{~m}$ tons during 2018-19 crop season. Nearly 1.6 times increment in production is attributed to increased yield levels that surpassed national productivity during 201819 crop season. The major reason behind this enhanced productivity is making timely access of inputs among which seed of improved varieties is major component. The seed supply of improved varieties has been exercised extensively as it was 445437 q during 2016-17 that reached to 830000 q during 2019-20 crop season and the targets for 2020-21 crop season is set to be $9,30,000$ q seed supply to farmers by the govt. or semi govt. agencies (Anonymous, 2019).

\subsection{Varietal replacement rate}

Varietal Replacement Rate (VRR) is one of the important factor in realizing higher crop productivity. The pace of progress in food production is largely depend upon the progress of seed programme that could able to supply good quality seed of high yielding varieties with superior genetics. Among the field crops, major share of breeder seed indent at national level is held by rice, wheat, chickpea, mungbean, soybean and rapeseed and mustard (Anonymous, 2020b). Among these crops, wheat has shown highest varietal replacement rate of $77.7 \%$ for the
Seed supply(q) of wheat in UP state by Govt/semi Govt agencies

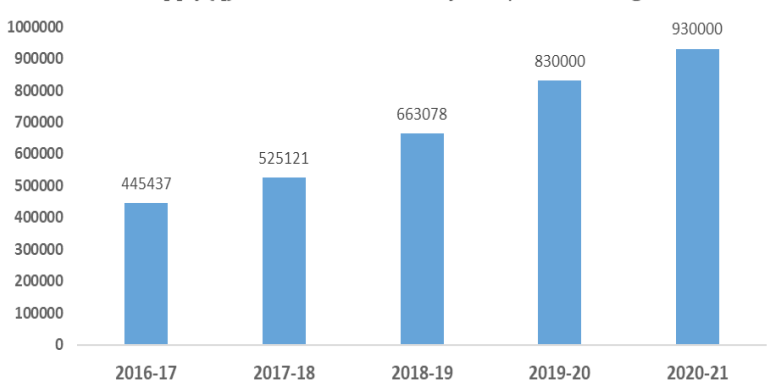

varieties released during last 10 years and for last 5 years it was $50.7 \%$ mainly due to occupancy of major wheat area by mega varieties especially HD 2967. This trend of higher varietal replacement is more prominent in UP state where 100 percent varietal replacement by the varieties released during last 10 years was observed since 2017-18 (Table.3). This indicates the adoption of latest wheat cultivars by the farmers in UP state. The reduction in breeder seed indent was also due to phasing out of old varieties from seed chain. The perusal of breeder seed indent (2965q) of advance varieties by UP state during 2019-20 indicated maximum share of HD 3086 (640q) followed by HD 2967 (545q), PBW 723 (500q) among 27 varieties in seed chain.

Table 3: Breeder seed indent and varietal replacement rate (VRR) in UP during 2015-16 to 2019-20

\begin{tabular}{cccc}
\hline \multirow{2}{*}{ Year } & \multicolumn{2}{c}{ Breeder seed Indent $(q)$} & \multirow{2}{*}{$\begin{array}{c}\text { VRR }(\%)<10 y r s \\
\text { old varieties }\end{array}$} \\
\cline { 2 - 3 } $2015-16$ & India & UP & $466(155)$ \\
$2016-17$ & $23492(185)$ & $3424(32)$ & 95 \\
$2017-18$ & $22013(148)$ & $2945(42)$ & 88 \\
$2018-19$ & $20322(141)$ & $3265(30)$ & 100 \\
$2019-20$ & $15701(144)$ & $2965(27)$ & 100 \\
\hline
\end{tabular}

Values in parenthesis are number of varieties in seed chain

\subsection{Future prospects}

Development, deployment and diffusion of climate resilient technologies, efficient resource utilization and supply of high yielding varieties/hybrids are required to attain desired growth rate that ultimately enhance farm productivity and profitability in order to alleviate poverty and vulnerability posed by climate change effects. Genetic enhancements made by crop improvement can

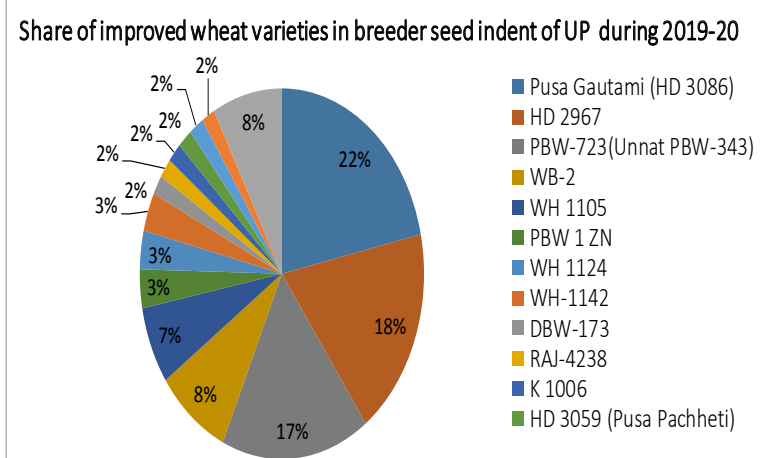


be translated into higher productivity with deployment of newly developed varieties. Among several approaches, improving varietal replacement rate (VRR) is one of the important factor in realizing higher crop productivity (Singh et al., 2019). The pace of progress in food production is largely depend upon the progress of seed programme that could able to supply good quality seed of high yielding varieties with superior genetics. The frontline demonstrations of wheat (WFLD) conducted during 2014-15 to 2018-19 indicated prospects for wheat production improvement (Table.4). During last 5 years a total of 594 WFLDs were conducted in UP state in which improved varieties showed average yield gain of 14.6\% over check varieties which are frequently used by the farmers (Anonymous, 2019b).

Table 4: Yield gain through improved varieties in UP during last 5 years

\begin{tabular}{ccccc}
\hline \multirow{2}{*}{ Year } & Frontline & \multicolumn{2}{c}{$\begin{array}{c}\text { Mean Grain yield }(\mathrm{q} / \\
\text { ha) }\end{array}$} & $\begin{array}{c}\text { Gain } \\
\text { demonstrations }\end{array}$ \\
\cline { 3 - 4 } & & $\begin{array}{c}\text { Improved } \\
\text { varieties }\end{array}$ & $\begin{array}{c}\text { Check } \\
\text { varieties }\end{array}$ & \\
\hline $2014-15$ & 57 & 36.97 & 31.54 & 17.22 \\
$2015-16$ & 94 & 44.25 & 38.98 & 13.52 \\
$2016-17$ & 77 & 50.98 & 44.81 & 13.77 \\
$2017-18$ & 174 & 46.67 & 40.59 & 14.98 \\
$2018-19$ & 192 & 47.36 & 41.69 & 13.60 \\
\hline
\end{tabular}

This indicated opportunities to take more area under improved varieties for realizing higher yield levels. By bridging the yield gap and providing timely input to farmers including improved seed may be helpful in increasing wheat productivity of UP upto $45.0 \mathrm{q} / \mathrm{ha}$ similar to Haryana and Punjab states. It can be concluded that the synergy between research, developmental and extension workers as well as seed industry can be helpful in enhancing wheat production that ultimately will make India a global leader to achieve the future demand of wheat.

\section{References}

1. Aggarwal PK. 2009. Global Climate Change and Indian Agriculture-Case Studies from the ICAR Network Project. New Delhi: Indian Council of Agricultural Research

2. Anonymous, 2015. ICAR-IIWBR. Vision 2050. Karnal: ICAR-Indian Institute of Wheat and Barley Research. Pp. 48.

3. Anonymous. 2019a. UP Department of Agriculture and Farmers Welfare: Achievements and opportunities. Directorate of Agriculture, UP Government, Lucknow, UP. Pp. 38.

4. Anonymous. 2019b. AICRP WandB. Director's Report. 59 $9^{\text {th }}$ All India Wheat and Barley Research Workers' Meet. August 24-26, 2019. Indore.
5. Anonymous. 2020a. Third Advance Estimates of Production of Foodgrains for 2019-20 as on 15.5.2020. Directorate of Economics and Statistics, DACandFW, Ministry of Agriculture and Farmers Welfare, Govt of India.

6. Anonymous. 2020b. AICRP on NSP Report: https:// aicrp.icar.gov.in/nsp/enhancement-in-varietalreplacement-rate-vrr-in-major-field-crops/

7. Chatrath R, Mishra B, Ortiz-Ferrara G, Singh SK and Joshi AK. 2007. Challenges to wheat production in South Asia. Euphytica,157:447-456.

8. Joshi AK, Mishra B, Chatrath R, Ortiz Ferrara G and Singh RP. 2007. Wheat improvement in India:Present status, emerging challenges and future prospects. Euphytica. 157:431-446. DOI: 10.1007/s10681-0079385-7

9. Nagarajan S. 2005. Can India produce enough wheat even by 2020? Current Science, 89(9): 1467-71.

10. Sendhil R, Jha Ankita, and Singh S. 2018. Extent of vulnerability in wheat producing agro-ecologies of India: Tracking from indicators of crosssection and multi-dimension data. Ecological Indicators. 89:771-780. DOI: 10.1016/j.ecolind.2018.02.053

11. Sendhil R, Kumar A, Singh S, Chatrath R and Singh GP. 2017. Framework for doubling the income of wheat producers' by 2022: Trends, pathway and drivers. Indian Journal of Economics and Development. 13:1-8

12. Sharma I, Chatrath R and Sendhil R. 2013. Research, policy and institutional dynamics in enhancing wheat production and productivity in India. In: Shetty PK, Ayyappan S, Swaminathan MS, editors. Climate Change and Sustainable Food Security. National Institute of Advance Studies. New Delhi: Bangalore and Indian Council of Agricultural Research; 2013. ISBN: 978-81-87663-76-8

13. Singh GP, Sendhil R and Chatrath R. 2017. Doubling farmers income in northeastern region of India by 2022: A roadmap for wheat producers. In: Souvenir Released during the 56th All India Wheat and Barley Research Workers' Meet; Varanasi: BHU

14. Singh RP, Chintagunta AD, Agarwal DK, Kureel RS and Jeevankumar SP. 2019. Varietal replacement rate: Prospects and challenges for global food security. Global Food Security. Online Journal 2019.

15. Yadav R, Singh SS, Singh GP and Prabhu KV. 2010. Wheat production in India: Technologies to face future challenges. Journal of Agricultural Science, 2(2): 164-173. 